\title{
New Urea and Thiourea Derivatives of Piperazine Doped with Febuxostat: Synthesis and Evaluation of Anti-TMV and Antimicrobial Activities
}

\author{
Reddivari Chenna Krishna Reddy, ${ }^{1}$ Syed Rasheed, ${ }^{1}$ Devineni Subba Rao, ${ }^{1}$ Shaik Adam, \\ Yellala Venkata Rami Reddy, ${ }^{1}$ and Chamarthi Naga Raju' \\ ${ }^{1}$ Department of Chemistry, Sri Venkateswara University, Tirupati, Andhra Pradesh-517 502, India \\ ${ }^{2}$ Department of Biochemistry, Sri Venkateswara University, Tirupati, Andhra Pradesh-517 502, India
}

Correspondence should be addressed to Chamarthi Naga Raju; rajuchamarthi10@gmail.com

Received 24 August 2013; Accepted 3 October 2013

Academic Editors: H. R. Appelt, C. Aragoncillo, G. A. Elmegeed, H. Miyabe, and H. Pellissier

Copyright (c) 2013 Reddivari Chenna Krishna Reddy et al. This is an open access article distributed under the Creative Commons Attribution License, which permits unrestricted use, distribution, and reproduction in any medium, provided the original work is properly cited.

\begin{abstract}
A series of new 4-(5-(3-cyano-4-isobutoxyphenyl)-4-methylthiazole-2-carbonyl)-N-(substituted phenyl)piperazine-1-carboxamides $\mathbf{8}(\mathbf{a}-\mathbf{e})$ /carbothioamides $\mathbf{8}(\mathbf{f}-\mathbf{j})$ were accomplished for biological interest by the simple addition of active functionalized arylisocyanates $7(\mathbf{a}-\mathbf{e})$ /arylisothiocyanates $7(\mathbf{f}-\mathbf{j})$ with 2-isobutoxy-5-(4-methyl-2-(piperazine-1-carbonyl)thiazol-5-yl)benzonitrile (4). Compound 4 was synthesized in high yields (94\%) by the condensation reaction of febuxostat (1) with piperazine using a selective reagent such as propylphosphonic anhydride $\left(\mathrm{T}_{3} \mathrm{P}\right)$. Antiviral activity against Tobacco mosaic virus (TMV) and antimicrobial activity of the synthesized compounds were evaluated. Biological data revealed that 4-nitrophenyl substituted urea 8d, and 3bromophenyl substituted thiourea 8f exhibited promising antiviral activities. Moreover, 4-fluorophenyl substituted urea 8a, 4nitrophenyl substituted urea 8d, 3-bromophenyl substituted thiourea $\mathbf{8 f}$, and 2,4-dichlorophenyl substituted thiourea $\mathbf{8 j}$ exhibited potent antimicrobial activity.
\end{abstract}

\section{Introduction}

Xanthine oxidase $(\mathrm{XO})$ is an enzyme that catalyzes the oxidation of hypoxanthine to xanthine and can further catalyze the oxidation of xanthine to uric acid [1]. The literature studies revealed that an increase in mean serum urate in both genders during the past four decades [2-4] and the underlying cause of gout is hyperuricemia. In human, the substance which acts as inhibitor of xanthine oxidase reduces the production of uric acid and several medications that inhibit xanthine oxidase are indicated for treatment of hyperuricemia and related medical conditions including gout [5]. Two types of XO inhibitors are in use: purine analogues, such as allopurinol (1) and oxypurinol (2), have long been employed in main therapy for the treatment of chronic gout in many countries, and nonpurine analogues, such as febuxostat (3) (Figure 1). Febuxostat (Adenuric $\mathbf{\nabla}$ ), 2-[3-cyano-4-(2-methylpropoxy)phenyl]4-methylthiazole-5-carboxylic acid is a nonpurine selective inhibitor of xanthine oxidase (XO) used for the treatment of hyperuricemia and gout and was approved in the USA. It is not expected to inhibit other enzymes involved in purine, pyrimidine synthesis, and metabolism at therapeutic concentrations [6-8].

Furthermore, it is well known that a number of nitrogen containing heterocyclic compounds exhibited a wide variety of biological activities. Among them, piperazine derivatives have owed their importance in many medicinal molecules. Piperazine derivatives were originally used in veterinary medicines which combat parasitic infections in poultry, stimulants at low doses, and hallucinations at higher level doses [9]. In addition to the nitrogen functionalities such as urea and thiourea which have been found in broad spectrum of biological activities like antidiabetic [10], anti-inflammatory [11], antiviral [12], antibacterial, antifungal, herbicidal [13, 14], antituberculosis [15-18], and antidepressant activity on central nervous system [19] as well as purification agents for the effluent of organic and inorganic molecules in industrial, agricultural, and mining industries [20]. Recently, some 
<smiles>O=c1ncnc2[nH][nH]cc1-2</smiles>

Allopurinol (1)<smiles>O=c1nc2[nH][nH]cc-2c(=O)[nH]1</smiles>

Oxypurinol (2)

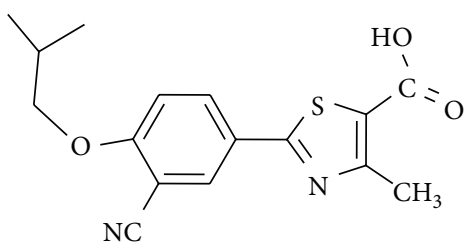

Febuxostat (3)<smiles>[X]C(Nc1ccccc1)N1CCN(C(=O)c2sc(-c3ccc(OCC(C)C)c(C#N)c3)nc2C)CC1</smiles>

FIgURE 1: Some biologically active molecules.

of urea-based compounds act as kinase inhibitors and as novel therapeutics in cancer treatment [21] due to their unique binding mode and kinase inhibition profile. Having more importance in pharmacological applications of urea and thiourea derivatives, there is a possibility to design more efficient urea and thiourea derivatives as antiviral and antimicrobial agents.

Based on the importance of urea and thiourea and piperazine derivatives and in the part of our research programme, we designed and synthesized a series of novel 5-(3cyano-4-isobutoxyphenyl)-4-methylthiazole-2-carbonyl)-N(substituted phenyl)piperazine-1-carboxamide/carbothiomide derivatives with a hope to obtain good results in the screening biological studies against Tobacco mosaic virus and antimicrobial pathogens (bacterial and fungal strains).

\section{Materials and Methods}

2.1. Chemistry. All chemicals and reagents used for the synthesis were commercially available, and AR grade solvents/reagents were used as such were received from SigmaAldrich and Merck. All solvents used for spectroscopic and other physical studies were reagent grade and were further purified by the literature methods [22]. All melting points (m.p) were obtained with a digital Guna melting point apparatus and are uncorrected. IR spectra were recorded on a Perkin Elmer 283 unit using $\mathrm{KBr}$ discs. ${ }^{1} \mathrm{H} /{ }^{13} \mathrm{C}$ NMR spectra were recorded on a Bruker $400 \mathrm{MHz}$ NMR spectrometer operating at $400 \mathrm{MHz}$ for ${ }^{1} \mathrm{H}$ and $100.25 \mathrm{MHz}$ for ${ }^{13} \mathrm{C}$ in DMSO- $d_{6}$ solvent and TMS was used as internal standard. Chemical shift values $(\delta)$ and coupling constants $(J)$ are reported in ppm and $\mathrm{Hz}$, respectively. Standard abbreviations indicating multiplicity are used as follows: "s" for singlet, " $\mathrm{d}$ " for doublet, "dd" for doublet of doublets, "t" for triplet, "q" for quartet, " $m$ " for multiplet, and "br" for broad. LC-MS spectra were recorded on a Jeol SX 102 DA/600 Mass spectrometer.
Elemental analyses were performed on a Thermo Finnigan Instrument at the University of Hyderabad, Hyderabad, India. Analytical thin-layer chromatography (TLC) was carried out on precoated plates and spots were visualized with UV light.

2.1.1. Synthetic Procedure for the Synthesis of 2-Isobutoxy-5-(4methyl-2-(piperazine-1-carbonyl)thiazol-5-yl)benzonitrile (4). Febuxostat (3) (2.97 g, $9.4 \mathrm{mmol})$ was dissolved in $50 \mathrm{~mL}$ of dry dichloromethane (DCM) in a flask and base and diisopropylethylamine (DIPEA) $(2.5 \mathrm{~mL}, 14.0 \mathrm{mmol})$ was added. The reaction mixture was stirred for $20 \mathrm{~min}$ at room temperature to get homogeneous solution. The reagent, $\mathrm{T}_{3} \mathrm{P}$ $(3.6 \mathrm{~mL}, 12.0 \mathrm{mmol})$ and piperazine $(0.81 \mathrm{~g}, 9.4 \mathrm{mmol})$ were added to the reaction mixture with stirring. Then, the reaction mixture was stirred vigorously for $8 \mathrm{~h}$ at room temperature. After completion of the reaction as checked by TLC, the solid was filtered off and recrystallized from methanol to afford 2-isobutoxy-5-(4-methyl-2-(piperazine1-carbonyl)thiazol-5-yl)benzonitrile (4) (3.54 g) (94\%). Mol. Wt 384, mp $154-156^{\circ} \mathrm{C}$. IR (KBr, $\left.v \mathrm{~cm}^{-1}\right)$ : 3334 (-N-H, str), 3015 (=C-H, str), 2240 (-CN, str), 1654 (-C=O, str). ${ }^{1} \mathrm{H}$ NMR $\left(\mathrm{DMSO}-d_{6}, 400 \mathrm{MHz}\right) \delta(\mathrm{ppm}): 0.92(\mathrm{~d}, 6 \mathrm{H}, J=7.6 \mathrm{~Hz}$, $\left.\left(\mathrm{CH}_{3}\right)_{2}-\mathrm{CH}-\right), 1.28-1.42\left(\mathrm{~m}, 1 \mathrm{H},\left(\mathrm{CH}_{3}\right)_{2}-\mathrm{CH}-\mathrm{CH}_{2}-\right), 2.43(\mathrm{~s}$, $\left.3 \mathrm{H},-\mathrm{CH}_{3}\right), 3.12\left(\mathrm{t}, 4 \mathrm{H}, J=6.8 \mathrm{~Hz},-\mathrm{CH}_{2}-\mathrm{N}-\mathrm{CH}_{2}-\right), 3.28(\mathrm{t}$, $\left.4 \mathrm{H}, J=6.8 \mathrm{~Hz},-\mathrm{CH}_{2}-\mathrm{N}-\mathrm{CH}_{2}-\right), 3.79(\mathrm{~d}, 2 \mathrm{H}, J=7.6 \mathrm{~Hz}$, $-\mathrm{O}-\mathrm{CH}_{2}-\mathrm{CH}-$ ), 6.98 (d, $\left.1 \mathrm{H}, J=6.4 \mathrm{~Hz}, \mathrm{Ar}-\mathrm{H}\right), 7.21$ (s, $1 \mathrm{H}$, Ar-H), 7.64 (d, $1 \mathrm{H}, J=6.0 \mathrm{~Hz}, \operatorname{Ar}-\mathrm{H})$. LC-MS ( $m / z, \%): 383$ $\left(\mathrm{M}-\mathrm{H}^{+}, 100\right)$.

2.1.2. Typical Procedure for the Synthesis of Title Urea/Thiourea Derivatives $\mathbf{8}(\mathbf{a}-\mathbf{j})$. The synthesized intermediate, 2 -isobutoxy-5-(4-methyl-2-(piperazine-1-carbonyl)thiazol-5-yl)benzonitrile (4) (250 mg, $0.65 \mathrm{mmol}), 1$-isocyanato-4-nitrobenzene $(7 \mathbf{d})(106.38 \mathrm{mg}, 0.65 \mathrm{mmol})$ and N,N-dimethylpiperazine $(0.13 \mathrm{~mL}, 0.98 \mathrm{mmol})$ were dissolved in $20 \mathrm{~mL}$ 
of THF in a flask and refluxed with vigorous stirring for $2.5 \mathrm{~h}$. After completion of the reaction as indicated by TLC, the reaction mixture was concentrated under reduced pressure to get crude product $\mathbf{8 d}$. The crude product was purified by column chromatography using $3: 7$ ratio of ethyl acetate and $n$-hexane as an eluent to get pure 4-(5-(3-cyano4-isobutoxyphenyl)-4-methylthiazole-2-carbonyl)-N-(4-nitrophenyl)piperazine-1-carboxamide (8d) (321 mg, 90\%). All the other title compounds were synthesized using the above experimental procedure.

\subsubsection{4-[2-(3-Cyano-4-isobutoxyphenyl)-4-methylthiazole-5-} carbonyl]-N-(4-fluorophenyl)piperazine-1-carboxamide (8a). Light brown solid, Yield: $85 \%, \mathrm{mp} 182-184^{\circ} \mathrm{C}$. IR (KBr, $v$ $\left.\mathrm{cm}^{-1}\right)$ : 3296 (-N-H, str), 3015 (=C-H, str), 2889 (-C-H, str), 2243 (-CN, str), 1676 (-C=O, str), 1638 (-C=O, str), 1167 (-CF, str); ${ }^{1} \mathrm{H}$ NMR (DMSO- $\left.d_{6}, 400 \mathrm{MHz}\right) \delta(\mathrm{ppm}): 0.94(\mathrm{~d}, 6 \mathrm{H}$, $\left.J=8.8 \mathrm{~Hz},\left(\mathrm{CH}_{3}\right)_{2}-\mathrm{CH}-\right), 1.28-1.42\left(\mathrm{~m}, 1 \mathrm{H},\left(\mathrm{CH}_{3}\right)_{2}-\mathrm{CH}-\right.$ $\mathrm{CH}_{2}-$ ), $2.56\left(\mathrm{~s}, 3 \mathrm{H},-\mathrm{CH}_{3}\right), 3.39\left(\mathrm{t}, 4 \mathrm{H}, J=7.2 \mathrm{~Hz},-\mathrm{CH}_{2}-\right.$ $\left.\mathrm{N}-\mathrm{CH}_{2}-\right), 3.68\left(\mathrm{t}, 4 \mathrm{H}, \mathrm{J}=6.8 \mathrm{~Hz},-\mathrm{CH}_{2}-\mathrm{N}-\mathrm{CH}_{2}-\right), 3.85$ (d, $2 \mathrm{H}, J=7.6 \mathrm{~Hz},-\mathrm{O}-\mathrm{CH}_{2}-\mathrm{CH}-$ ), $7.36-7.43$ (m, $2 \mathrm{H}$, Ar$\mathrm{H}), 7.61(\mathrm{~d}, 2 \mathrm{H}, J=6.4 \mathrm{~Hz}, \mathrm{Ar}-\mathrm{H}), 7.73-7.81(\mathrm{~m}, 3 \mathrm{H}, \mathrm{Ar}-\mathrm{H})$, $9.51(\mathrm{~s}, 1 \mathrm{H},-\mathrm{NH}-\mathrm{C}=\mathrm{O}) ;{ }^{13} \mathrm{C}$ NMR (DMSO- $\left.d_{6}, 100.25 \mathrm{MHz}\right)$ $\delta$ (ppm): $17.4\left(\mathrm{C}_{35}\right), 18.9\left(\mathrm{C}_{33,34}\right), 31.2\left(\mathrm{C}_{32}\right), 48.6\left(\mathrm{C}_{16,20}\right), 51.2$ $\left(\mathrm{C}_{17,19}\right), 73.1\left(\mathrm{C}_{31}\right), 104.6\left(\mathrm{C}_{1}\right), 113.9\left(\mathrm{C}_{25,27}\right), 114.6\left(\mathrm{C}_{5}\right), 118.2$ $\left(\mathrm{C}_{11}\right), 119.4\left(\mathrm{C}_{7}\right), 120.1\left(\mathrm{C}_{24,28}\right), 123.4\left(\mathrm{C}_{3}\right), 126.2\left(\mathrm{C}_{2}\right), 130.4$ $\left(\mathrm{C}_{4}\right), 136.6\left(\mathrm{C}_{23}\right), 151.3\left(\mathrm{C}_{6}\right), 154.8\left(\mathrm{C}_{10}\right), 158.3\left(\mathrm{C}_{21}\right), 162.2$ $\left(\mathrm{C}_{13}\right), 165.7\left(\mathrm{C}_{26}\right), 166.2\left(\mathrm{C}_{8}\right)$; LC-MS $(\mathrm{m} / z, \%): 520\left(\mathrm{M}-\mathrm{H}^{+}\right.$, 100), $410\left(\mathrm{M}-\mathrm{H}^{+}-110,30\right), 382\left(\mathrm{M}-\mathrm{H}^{+}-138,73\right)$; Anal. Calcd. for $\mathrm{C}_{27} \mathrm{H}_{28} \mathrm{FN}_{5} \mathrm{O}_{3} \mathrm{~S}$ : C, 62.17; H, 5.41; N, 13.43. Found: C, 61.93; $\mathrm{H}, 5.34 ; \mathrm{N}, 13.48 \%$.

2.1.4. N-(4-Bromophenyl)-4-[2-(3-cyano-4-isobutoxyphenyl)4-methylthiazole-5-carbonyl]piperazine-1-carboxamide (8b). White solid, Yield: $81 \%, \mathrm{mp} 163-165^{\circ} \mathrm{C}$. IR $\left(\mathrm{KBr}, v \mathrm{~cm}^{-1}\right)$ : 3312 (-N-H, str), 3018 (=C-H, str), 2885 (-C-H, str), 2235 ( $-\mathrm{CN}$, str), 1672 ( $-\mathrm{C}=\mathrm{O}$, str), $1646(-\mathrm{C}=\mathrm{O}$, str), $748(-\mathrm{C}-\mathrm{Br}$, str); ${ }^{1} \mathrm{H}$ NMR (DMSO- $\left.d_{6}, 400 \mathrm{MHz}\right) \delta(\mathrm{ppm}): 0.89$ (d, $6 \mathrm{H}$, $\left.J=7.6 \mathrm{~Hz},\left(\mathrm{CH}_{3}\right)_{2}-\mathrm{CH}-\right), 1.21-1.33\left(\mathrm{~m}, 1 \mathrm{H},\left(\mathrm{CH}_{3}\right)_{2}-\mathrm{CH}-\right.$ $\left.\mathrm{CH}_{2}-\right), 2.51\left(\mathrm{~s}, 3 \mathrm{H},-\mathrm{CH}_{3}\right), 3.34\left(\mathrm{t}, 4 \mathrm{H}, \mathrm{J}=7.2 \mathrm{~Hz},-\mathrm{CH}_{2}-\right.$ $\left.\mathrm{N}-\mathrm{CH}_{2}-\right), 3.51\left(\mathrm{t}, 4 \mathrm{H}, \mathrm{J}=7.2 \mathrm{~Hz},-\mathrm{CH}_{2}-\mathrm{N}-\mathrm{CH}_{2}-\right), 3.74(\mathrm{~d}$, $\left.2 \mathrm{H}, J=6.8 \mathrm{~Hz},-\mathrm{O}-\mathrm{CH}_{2}-\mathrm{CH}-\right), 7.27(\mathrm{~d}, 1 \mathrm{H}, J=6.8 \mathrm{~Hz}, \mathrm{Ar}-$ $\mathrm{H}), 7.18(\mathrm{~d}, 2 \mathrm{H}, J=6.4 \mathrm{~Hz}, \mathrm{Ar}-\mathrm{H}), 7.26-7.39$ (m, 4H, Ar-H), $9.28(\mathrm{~s}, 1 \mathrm{H},-\mathrm{NH}-\mathrm{C}=\mathrm{O}) ;{ }^{13} \mathrm{C}$ NMR $\left(\mathrm{DMSO}_{-}, d_{6}, 100.25 \mathrm{MHz}\right)$ $\delta$ (ppm): $17.1\left(\mathrm{C}_{35}\right), 17.9\left(\mathrm{C}_{33,34}\right), 33.4\left(\mathrm{C}_{32}\right), 49.8\left(\mathrm{C}_{16,20}\right), 51.4$ $\left(\mathrm{C}_{17,19}\right), 72.8\left(\mathrm{C}_{31}\right), 104.4\left(\mathrm{C}_{1}\right), 113.6\left(\mathrm{C}_{25,27}\right), 114.8\left(\mathrm{C}_{5}\right), 117.5$ $\left(\mathrm{C}_{11}\right), 118.1\left(\mathrm{C}_{7}\right), 121.4\left(\mathrm{C}_{24,28}\right), 122.7\left(\mathrm{C}_{26}\right), 124.5\left(\mathrm{C}_{3}\right), 125.8$ $\left(\mathrm{C}_{2}\right), 128.7\left(\mathrm{C}_{4}\right), 136.3\left(\mathrm{C}_{23}\right), 152.6\left(\mathrm{C}_{6}\right), 154.7\left(\mathrm{C}_{10}\right), 157.2$ $\left(\mathrm{C}_{21}\right), 160.1\left(\mathrm{C}_{13}\right), 164.7\left(\mathrm{C}_{8}\right)$; LC-MS $(\mathrm{m} / z, \%): 582\left(\mathrm{M}-\mathrm{H}^{+}+2\right.$, 97), $580\left(\mathrm{M}-\mathrm{H}^{+}, 100\right), 410\left(\mathrm{M}-\mathrm{H}^{+}-170,46\right)$.

2.1.5. 4-[2-(3-Cyano-4-isobutoxyphenyl)-4-methylthiazole-5carbonyl]-N-(2-nitrophenyl)piperazine-1-carboxamide (8c). Brown powdered solid, Yield: $89 \%, \mathrm{mp} 176-178^{\circ} \mathrm{C}$. IR (KBr, $v$ $\mathrm{cm}^{-1}$ ): 3320 (-N-H, str), 3051 (=C-H, str), 2892 (-C-H, str), 2248 (-CN, str), 1674 (-C=O, str), 1640 (-C=O, str), 1546 (- $\mathrm{NO}_{2}$ (aromatic), asymstr); ${ }^{1} \mathrm{H}$ NMR (DMSO- $\left.d_{6}, 400 \mathrm{MHz}\right)$ $\delta$ (ppm): 0.98 (d, $\left.6 \mathrm{H}, J=7.2 \mathrm{~Hz},\left(\mathrm{CH}_{3}\right)_{2}-\mathrm{CH}-\right), 1.24-1.31$ $\left(\mathrm{m}, 1 \mathrm{H},\left(\mathrm{CH}_{3}\right)_{2}-\mathrm{CH}-\mathrm{CH}_{2}-\right), 2.73\left(\mathrm{~s}, 3 \mathrm{H},-\mathrm{CH}_{3}\right), 3.55(\mathrm{t}$, $\left.4 \mathrm{H}, J=6.8 \mathrm{~Hz},-\overline{\mathrm{CH}}_{2}-\mathrm{N}-\mathrm{CH}_{2}-\right), 3.68(\mathrm{t}, 4 \mathrm{H}, J=7.2 \mathrm{~Hz}$, $\left.-\mathrm{CH}_{2}-\mathrm{N}-\mathrm{CH}_{2}-\right), 3.96\left(\mathrm{~d}, 2 \mathrm{H}, J=7.6 \mathrm{~Hz},-\mathrm{O}-\mathrm{CH}_{2}-\mathrm{CH}-\right)$, $7.35(\mathrm{~d}, 1 \mathrm{H}, J=6.4 \mathrm{~Hz}, \mathrm{Ar}-\mathrm{H}), 7.64-7.79(\mathrm{~m}, 4 \overline{\mathrm{H}}, \mathrm{Ar}-\mathrm{H})$, 8.18-8.26 (m, 2H, Ar-H), 9.88 (s, 1H, -NH-C=O); ${ }^{13} \mathrm{C}$ NMR $\left(\mathrm{DMSO}-d_{6}, 100.25 \mathrm{MHz}\right) \delta(\mathrm{ppm}): 17.8\left(\mathrm{C}_{35}\right), 17.9\left(\mathrm{C}_{33,34}\right)$, $33.7\left(\mathrm{C}_{32}\right), 50.1\left(\mathrm{C}_{16,20}\right), 58.2\left(\mathrm{C}_{17,19}\right), 73.6\left(\mathrm{C}_{31}\right), 105.3\left(\mathrm{C}_{1}\right)$, $115.4\left(\mathrm{C}_{5}\right), 116.5\left(\mathrm{C}_{11}\right), 120.8\left(\mathrm{C}_{7}\right), 122.7\left(\mathrm{C}_{28}\right), 124.6\left(\mathrm{C}_{26}\right)$, $125.7\left(\mathrm{C}_{25,3}\right), 129.8\left(\mathrm{C}_{27}\right), 131.7\left(\mathrm{C}_{2,4}\right), 135.6\left(\mathrm{C}_{23}\right), 143.5\left(\mathrm{C}_{24}\right)$, $152.1\left(\mathrm{C}_{6}\right), 155.3\left(\mathrm{C}_{10}\right), 156.8\left(\mathrm{C}_{21}\right), 160.3\left(\mathrm{C}_{13}\right), 164.3\left(\mathrm{C}_{8}\right)$; LC-MS ( $m / z, \%): 547\left(\mathrm{M}-\mathrm{H}^{+}, 100\right), 410\left(\mathrm{M}-\mathrm{H}^{+}-137,38\right), 382$ $\left(\mathrm{M}-\mathrm{H}^{+}-165,71\right)$.

2.1.6. 4-[2-(3-Cyano-4-isobutoxyphenyl)-4-methylthiazole-5carbonyl]-N-(4-nitrophenyl)piperazine-1-carboxamide (8d). Yellow solid, Yield: $90 \%, \mathrm{mp} 181-183^{\circ} \mathrm{C}$. IR $\left(\mathrm{KBr}, v \mathrm{~cm}^{-1}\right)$ : 3315 (-N-H, str), 3042 (=C-H, str), 2896 (-C-H, str), 2257 (-CN, str), 1678 ( $-\mathrm{C}=\mathrm{O}$, str), 1635 ( $-\mathrm{C}=\mathrm{O}$, str), $1542\left(-\mathrm{NO}_{2}\right.$ (aromatic), asymstr); ${ }^{1} \mathrm{H}$ NMR (DMSO- $\left.d_{6}, 400 \mathrm{MHz}\right) \delta$ (ppm): $1.04\left(\mathrm{~d}, 6 \mathrm{H}, J=7.2 \mathrm{~Hz},\left(\mathrm{CH}_{3}\right)_{2}-\mathrm{CH}-\right), 1.19-1.28$ $\left(\mathrm{m}, 1 \mathrm{H},\left(\mathrm{CH}_{3}\right)_{2}-\mathrm{CH}-\mathrm{CH}_{2}-\right), 2.67\left(\mathrm{~s}, 3 \mathrm{H},-\mathrm{CH}_{3}\right), 3.42(\mathrm{t}$, $\left.4 \mathrm{H}, J=7.2 \mathrm{~Hz},-\overline{\mathrm{CH}}_{2}-\mathrm{N}-\mathrm{CH}_{2}-\right), 3.68(\mathrm{t}, 4 \mathrm{H}, J=7.2 \mathrm{~Hz}$, $\left.-\mathrm{CH}_{2}-\mathrm{N}-\mathrm{CH}_{2}-\right), 3.92\left(\mathrm{~d}, 2 \mathrm{H}, \mathrm{J}=6.8 \mathrm{~Hz},-\mathrm{O}-\mathrm{CH}_{2}-\mathrm{CH}-\right)$, $7.35(\mathrm{~d}, 1 \mathrm{H}, J=6.4 \mathrm{~Hz}, \mathrm{Ar}-\mathrm{H}), 7.54-7.68(\mathrm{~m}, 4 \mathrm{H}, \mathrm{Ar}-\mathrm{H})$, $8.24(\mathrm{~d}, 2 \mathrm{H}, \mathrm{J}=6.8 \mathrm{~Hz}, \mathrm{Ar}-\mathrm{H}), 10.05(\mathrm{~s}, 1 \mathrm{H},-\mathrm{NH}-\mathrm{C}=\mathrm{O})$; ${ }^{13} \mathrm{C}$ NMR (DMSO- $\left.d_{6}, 100.25 \mathrm{MHz}\right) \delta(\mathrm{ppm}): 17.5\left(\mathrm{C}_{35}\right), 17.9$ $\left(\mathrm{C}_{33,34}\right), 34.1\left(\mathrm{C}_{32}\right), 49.5\left(\mathrm{C}_{16,20}\right), 55.6\left(\mathrm{C}_{17,19}\right), 71.9\left(\mathrm{C}_{31}\right)$, $106.2\left(\mathrm{C}_{1}\right), 116.9\left(\mathrm{C}_{5}\right), 117.6\left(\mathrm{C}_{11}\right), 120.3\left(\mathrm{C}_{7}\right), 122.7\left(\mathrm{C}_{24,28}\right)$, $125.4\left(\mathrm{C}_{25,27}\right), 125.9\left(\mathrm{C}_{3}\right), 132.4\left(\mathrm{C}_{2,4}\right), 141.6\left(\mathrm{C}_{26}\right), 145.8\left(\mathrm{C}_{23}\right)$, $150.3\left(\mathrm{C}_{6}\right), 155.4\left(\mathrm{C}_{10}\right), 156.7\left(\mathrm{C}_{21}\right), 159.4\left(\mathrm{C}_{13}\right), 165.1\left(\mathrm{C}_{8}\right)$;

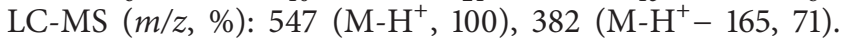
Anal. Calcd. for $\mathrm{C}_{27} \mathrm{H}_{28} \mathrm{~N}_{6} \mathrm{O}_{5} \mathrm{~S}$ : C, 59.11; H, 5.14; N, 15.32 . Found: C, 58.96; H, 5.03; N, 15.20\%.

2.1.7. N-(3-Chloro-4-fluorophenyl)-4-[2-(3-cyano-4-isobutoxisobutoxyphenylyphenyl)-4-methylthiazole-5-carbonyl]piperazine-1-carboxamide (8e). White solid, Yield: $86 \%$, mp 201$203^{\circ} \mathrm{C}$. IR (KBr, $\left.v \mathrm{~cm}^{-1}\right)$ : $3337(-\mathrm{N}-\mathrm{H}, \mathrm{str}), 3025$ (=C-H, str), 2887 (-C-H, str), 2248 (-CN, str), 1675 (-C=O, str), 1630 (-C=O, str), 1154 (-C-F, str), 823 (-C-Cl, str); ${ }^{1} \mathrm{H}$ NMR $\left(\mathrm{DMSO}-d_{6}, 400 \mathrm{MHz}\right) \delta(\mathrm{ppm}): 0.91(\mathrm{~d}, 6 \mathrm{H}, J=7.2 \mathrm{~Hz}$, $\left.\left(\mathrm{CH}_{3}\right)_{2}-\mathrm{CH}-\right), 1.01-1.12\left(\mathrm{~m}, 1 \mathrm{H},\left(\mathrm{CH}_{3}\right)_{2}-\mathrm{CH}-\mathrm{CH}_{2}-\right), 2.49$ (s, $\left.3 \mathrm{H},-\mathrm{CH}_{3}\right), 3.57\left(\mathrm{t}, 4 \mathrm{H}, \mathrm{J}=6.8 \mathrm{~Hz},-\mathrm{CH}_{2}-\mathrm{N}-\mathrm{CH}_{2}-\right), 3.61(\mathrm{t}$, $\left.4 \mathrm{H}, J=6.4 \mathrm{~Hz},-\mathrm{CH}_{2}-\mathrm{N}-\mathrm{CH}_{2}-\right), 3.91(\mathrm{~d}, 2 \mathrm{H}, J=6.4 \mathrm{~Hz}$, -O- $\mathrm{CH}_{2}-\mathrm{CH}-$ ), 7.29-7.38 (m, 3H, Ar-H), 7.52 (s, 1H, Ar-H), 7.63-7.72 (m, 2H, Ar-H), 9.15 (s, 1H, -NH-C $=\mathrm{O}) ;{ }^{13} \mathrm{C} \mathrm{NMR}$ $\left(\mathrm{DMSO}-d_{6}, 100.25 \mathrm{MHz}\right) \delta(\mathrm{ppm}): 17.9\left(\mathrm{C}_{35}\right), 18.2\left(\mathrm{C}_{33,34}\right)$, $34.5\left(\mathrm{C}_{32}\right), 48.7\left(\mathrm{C}_{16,20}\right), 54.8\left(\mathrm{C}_{17,19}\right), 71.2\left(\mathrm{C}_{31}\right), 105.4\left(\mathrm{C}_{1}\right)$, $115.3\left(\mathrm{C}_{5}\right), 116.1\left(\mathrm{C}_{11}\right), 117.3\left(\mathrm{C}_{27}\right), 118.8\left(\mathrm{C}_{7}\right), 123.4\left(\mathrm{C}_{24,28}\right)$, $123.9\left(\mathrm{C}_{25}\right), 126.3\left(\mathrm{C}_{3}\right), 131.1\left(\mathrm{C}_{2,4}\right), 135.2\left(\mathrm{C}_{23}\right), 152.1\left(\mathrm{C}_{6}\right), 154.3$ $\left(\mathrm{C}_{10}\right), 154.8\left(\mathrm{C}_{26}\right), 158.9\left(\mathrm{C}_{21}\right), 160.8\left(\mathrm{C}_{13}\right), 163.7\left(\mathrm{C}_{8}\right)$; LC-MS $(\mathrm{m} / z, \%): 556\left(\mathrm{M}-\mathrm{H}^{+}+2,33\right), 554\left(\mathrm{M}-\mathrm{H}^{+}, 100\right), 382\left(\mathrm{M}-\mathrm{H}^{+}-\right.$ $172,64)$.

2.1.8. N-(3-Bromophenyl)-4-[2-(3-cyano-4-isobutoxyphenyl)4-methylthiazole-5-carbonyl]piperazine-1-carbothioamide (8f). White solid, Yield: $83 \%, \mathrm{mp} 167-169^{\circ} \mathrm{C}$. IR (KBr, $v$ $\mathrm{cm}^{-1}$ ): 3287 (-N-H, str), 3015 (=C-H, str), 2881 (-C-H, 
str), 2232 (-CN, str), 1673 ( $-\mathrm{C}=\mathrm{O}$, str), 1187 ( $-\mathrm{C}=\mathrm{S}$, str), 754 (-C-Br, str); ${ }^{1} \mathrm{H}$ NMR (DMSO- $\left.d_{6}, 400 \mathrm{MHz}\right) \delta$ (ppm): 0.93 $\left(\mathrm{d}, 6 \mathrm{H}, J=7.2 \mathrm{~Hz},\left(\mathrm{CH}_{3}\right)_{2}-\mathrm{CH}-\right), 1.32-1.38\left(\mathrm{~m}, 1 \mathrm{H},\left(\mathrm{CH}_{3}\right)_{2}-\right.$ $\left.\mathrm{CH}-\mathrm{CH}_{2}-\right), 2.43\left(\mathrm{~s}, 3 \mathrm{H},-\mathrm{CH}_{3}\right), 3.61(\mathrm{t}, 4 \mathrm{H}, \mathrm{J}=7.6 \mathrm{~Hz}$, $-\overline{\mathrm{CH}}_{2}-\mathrm{N}-\mathrm{CH}_{2}-$ ), $3.75\left(\mathrm{t}, 4 \mathrm{H}, \mathrm{J}=7.2 \mathrm{~Hz},-\mathrm{CH}_{2}-\mathrm{N}-\mathrm{CH}_{2}-\right.$ ), $3.84\left(\mathrm{~d}, 2 \mathrm{H}, \mathrm{J}=6.8 \mathrm{~Hz},-\mathrm{O}-\mathrm{CH}_{2}-\mathrm{CH}-\right), 6.47-6.53(\mathrm{~m}$, $4 \mathrm{H}, \operatorname{Ar}-\mathrm{H}), 7.35(\mathrm{~d}, 1 \mathrm{H}, J=6.4 \mathrm{~Hz}, \mathrm{Ar}-\mathrm{H}), 7.61-7.72(\mathrm{~m}$, $2 \mathrm{H}, \mathrm{Ar}-\mathrm{H}$ ), 9.76 (s, $1 \mathrm{H},-\mathrm{NH}-\mathrm{C}=\mathrm{O}) ;{ }^{13} \mathrm{C}$ NMR (DMSO- $d_{6}$, $100.25 \mathrm{MHz}) \delta(\mathrm{ppm}): 18.4\left(\mathrm{C}_{35}\right), 18.5\left(\mathrm{C}_{33,34}\right), 32.1\left(\mathrm{C}_{32}\right), 47.3$ $\left(\mathrm{C}_{16,20}\right), 51.4\left(\mathrm{C}_{17,19}\right), 72.8\left(\mathrm{C}_{31}\right), 103.2\left(\mathrm{C}_{1}\right), 115.6\left(\mathrm{C}_{5}\right), 115.8$ $\left(\mathrm{C}_{11}\right), 116.2\left(\mathrm{C}_{7}\right), 124.1\left(\mathrm{C}_{25}\right), 124.8\left(\mathrm{C}_{24,28}\right), 125.7\left(\mathrm{C}_{3}\right), 126.4$ $\left(\mathrm{C}_{26}\right), 129.3\left(\mathrm{C}_{27}\right), 133.5\left(\mathrm{C}_{2,4}\right), 137.7\left(\mathrm{C}_{23}\right), 158.9\left(\mathrm{C}_{6}\right), 159.2$ $\left(\mathrm{C}_{10}\right), 163.4\left(\mathrm{C}_{13}\right), 166.4\left(\mathrm{C}_{8}\right), 175.1\left(\mathrm{C}_{21}\right)$; LC-MS $(\mathrm{m} / z, \%)$ : $598\left(\mathrm{M}-\mathrm{H}^{+}+2,97\right), 596\left(\mathrm{M}-\mathrm{H}^{+}, 100\right), 382\left(\mathrm{M}-\mathrm{H}^{+}-214,58\right)$.

2.1.9. 4-[2-(3-Cyano-4-isobutoxyphenyl)-4-methylthiazole-5carbonyl]-N-(4-nitrophenyl)piperazine-1-carbothioamide

(8g). Brown solid, Yield: $86 \%, \mathrm{mp} 171-173^{\circ} \mathrm{C}$. IR (KBr, $v$ $\mathrm{cm}^{-1}$ ): 3293 (-N-H, str), 3022 (=C-H, str), 2887 (-C-H, str), 2235 (-CN, str), 1678 ( $-\mathrm{C}=\mathrm{O}$, str), $1536\left(-\mathrm{NO}_{2}\right.$ (aromatic), asymstr), 1195 (-C=S, str); ${ }^{1} \mathrm{H}$ NMR (DMSO- $\left.d_{6}, 400 \mathrm{MHz}\right)$ $\delta$ (ppm): $0.92\left(\mathrm{~d}, 6 \mathrm{H}, J=6.8 \mathrm{~Hz},\left(\mathrm{CH}_{3}\right)_{2}-\mathrm{CH}-\right), 1.11-1.19$ $\left(\mathrm{m}, 1 \mathrm{H},\left(\mathrm{CH}_{3}\right)_{2}-\mathrm{CH}-\mathrm{CH}_{2}-\right), 2.78\left(\mathrm{~s}, 3 \mathrm{H},-\mathrm{CH}_{3}\right), 3.59(\mathrm{t}$, $\left.4 \mathrm{H}, J=7.2 \mathrm{~Hz},-\overline{\mathrm{CH}}_{2}-\mathrm{N}-\mathrm{CH}_{2}-\right), 3.82(\mathrm{t}, 4 \mathrm{H}, J=7.2 \mathrm{~Hz}$, $-\mathrm{CH}_{2}-\mathrm{N}-\mathrm{CH}_{2}-$ ), 3.91 (d, $\left.2 \mathrm{H}, \mathrm{J}=6.4 \mathrm{~Hz},-\mathrm{O}-\mathrm{CH}_{2}-\mathrm{CH}-\right)$, 7.28 (s, 1H, Ar-H), 7.38 (d, 1H, J = 6.8 Hz, Ar-H), 7.61-7.71 $(\mathrm{m}, 3 \mathrm{H}, \mathrm{Ar}-\mathrm{H}), 8.22(\mathrm{~d}, 2 \mathrm{H}, J=6.0 \mathrm{~Hz}, \mathrm{Ar}-\mathrm{H}), 9.61$ (s, $1 \mathrm{H}$, -NH-C $=\mathrm{O}) ;{ }^{13} \mathrm{C}$ NMR (DMSO- $\left.d_{6}, 100.25 \mathrm{MHz}\right) \delta(\mathrm{ppm})$ : $18.7\left(\mathrm{C}_{35}\right), 18.8\left(\mathrm{C}_{33,34}\right), 33.6\left(\mathrm{C}_{32}\right), 45.1\left(\mathrm{C}_{16,20}\right), 50.8\left(\mathrm{C}_{17,19}\right)$, $72.4\left(\mathrm{C}_{31}\right), 103.4\left(\mathrm{C}_{1}\right), 114.7\left(\mathrm{C}_{5}\right), 115.1\left(\mathrm{C}_{11}\right), 116.8\left(\mathrm{C}_{7}\right), 124.3$ $\left(\mathrm{C}_{25,27}\right), 124.6\left(\mathrm{C}_{24,28}\right), 125.0\left(\mathrm{C}_{3}\right), 132.5\left(\mathrm{C}_{2,4}\right), 141.5\left(\mathrm{C}_{23}\right)$, $145.2\left(\mathrm{C}_{26}\right), 160.2\left(\mathrm{C}_{6}\right), 160.3\left(\mathrm{C}_{10}\right), 164.5\left(\mathrm{C}_{13}\right), 166.7\left(\mathrm{C}_{8}\right)$,

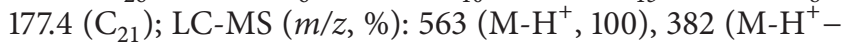
181, 66). Anal. Calcd. for $\mathrm{C}_{27} \mathrm{H}_{28} \mathrm{~N}_{6} \mathrm{O}_{4} \mathrm{~S}_{2}$ : C, 57.43; $\mathrm{H}, 5.00 ; \mathrm{N}$, 14.88. Found: C, 57.36; H, 4.94; N, 14.85\%.

\subsubsection{N-(4-Chlorophenyl)-4-[2-(3-cyano-4-isobutoxyphenyl)- 4-methylthiazole-5-carbonyl]piperazine-1-carbothioamide}

(8h). Light orange solid, Yield: $83 \%$, mp $188-190^{\circ} \mathrm{C}$. IR $\left(\mathrm{KBr}, v \mathrm{~cm}^{-1}\right)$ : $3282(-\mathrm{N}-\mathrm{H}$, str), 3021 (=C-H, str), 2884 (-C-H, str), 2236 ( $-\mathrm{CN}$, str), 1674 ( $-\mathrm{C}=\mathrm{O}$, str), $1182(-\mathrm{C}=\mathrm{S}$, str), 794 (-C-Cl, str); ${ }^{1} \mathrm{H}$ NMR (DMSO-d $\left.6,400 \mathrm{MHz}\right) \delta$ (ppm): $0.96\left(\mathrm{~d}, 6 \mathrm{H}, J=7.2 \mathrm{~Hz},\left(\mathrm{CH}_{3}\right)_{2}-\mathrm{CH}-\right), 1.05-1.11$ $\left(\mathrm{m}, 1 \mathrm{H},\left(\mathrm{CH}_{3}\right)_{2}-\mathrm{CH}-\mathrm{CH}_{2}-\right), 2.75\left(\mathrm{~s}, 3 \mathrm{H},-\mathrm{CH}_{3}\right), 3.54(\mathrm{t}$, $\left.4 \mathrm{H}, J=7.2 \mathrm{~Hz},-\overline{\mathrm{CH}}_{2}-\mathrm{N}-\mathrm{CH}_{2}-\right), 3.80(\mathrm{t}, 4 \mathrm{H}, J=7.2 \mathrm{~Hz}$, $\left.-\mathrm{CH}_{2}-\mathrm{N}-\mathrm{CH}_{2}-\right), 3.92\left(\mathrm{~d}, 2 \mathrm{H}, \mathrm{J}=6.8 \mathrm{~Hz},-\mathrm{O}-\mathrm{CH}_{2}-\mathrm{CH}-\right)$, 6.88 (d, 2H, J = 6.8 Hz, Ar-H), 7.27-7.41 (m, 4H, Ar-H), 7.64 $(\mathrm{d}, 1 \mathrm{H}, J=6.4 \mathrm{~Hz}, \mathrm{Ar}-\mathrm{H}), 9.52(\mathrm{~s}, 1 \mathrm{H},-\mathrm{NH}-\mathrm{C}=\mathrm{O}) ;{ }^{13} \mathrm{C} \mathrm{NMR}$ $\left(\mathrm{DMSO}_{-} d_{6}, 100.25 \mathrm{MHz}\right) \delta(\mathrm{ppm}): 18.1\left(\mathrm{C}_{35}\right), 18.4\left(\mathrm{C}_{33,34}\right)$, $32.7\left(\mathrm{C}_{32}\right), 45.0\left(\mathrm{C}_{16,20}\right), 52.4\left(\mathrm{C}_{17,19}\right), 72.1\left(\mathrm{C}_{31}\right), 103.8\left(\mathrm{C}_{1}\right)$, $114.9\left(\mathrm{C}_{5}\right), 116.7\left(\mathrm{C}_{11}\right), 116.8\left(\mathrm{C}_{7}\right), 124.3\left(\mathrm{C}_{3}\right), 129.7\left(\mathrm{C}_{25,27}\right)$, $130.3\left(\mathrm{C}_{24,28}\right), 132.2\left(\mathrm{C}_{2,4}\right), 134.5\left(\mathrm{C}_{26}\right), 136.7\left(\mathrm{C}_{23}\right), 159.6\left(\mathrm{C}_{6}\right)$, $160.5\left(\mathrm{C}_{10}\right), 163.7\left(\mathrm{C}_{13}\right), 166.2\left(\mathrm{C}_{8}\right), 175.3\left(\mathrm{C}_{21}\right)$; LC-MS $(\mathrm{m} / z$, $\%): 554\left(\mathrm{M}-\mathrm{H}^{+}+2,33\right), 552\left(\mathrm{M}-\mathrm{H}^{+}, 100\right)$.

2.1.11. 4-[2-(3-Cyano-4-isobutoxyphenyl)-4-methylthiazole-5carbonyl]-N-(2,6-difluorophenyl)piperazine-1-carbothioamide (8i). White solid, Yield: $83 \%, \mathrm{mp} 214-216^{\circ} \mathrm{C}$. IR $(\mathrm{KBr}$, $\left.v \mathrm{~cm}^{-1}\right): 3285(-\mathrm{N}-\mathrm{H}, \mathrm{str}), 3024$ (=C-H, str), $2892(-\mathrm{C}-\mathrm{H}$, str), 2241 (-CN, str), 1680 ( $-\mathrm{C}=\mathrm{O}$, str), 1190 (-C=S, str), 1178 (-C-F, str); ${ }^{1} \mathrm{H}$ NMR (DMSO- $\left.d_{6}, 400 \mathrm{MHz}\right) \delta(\mathrm{ppm}): 0.96$ $\left(\mathrm{d}, 6 \mathrm{H}, J=7.6 \mathrm{~Hz},\left(\mathrm{CH}_{3}\right)_{2}-\mathrm{CH}-\right), 1.09-1.17\left(\mathrm{~m}, 1 \mathrm{H},\left(\mathrm{CH}_{3}\right)_{2}-\right.$ $\left.\mathrm{C} \underline{\mathrm{H}}-\mathrm{CH}_{2}-\right), 2.78\left(\mathrm{~s}, 3 \mathrm{H},-\mathrm{CH}_{3}\right), 3.62(\mathrm{t}, 4 \mathrm{H}, J=6.8 \mathrm{~Hz}$, $\left.-\overline{\mathrm{CH}}_{2}-\mathrm{N}-\mathrm{CH}_{2}-\right), 3.73\left(\mathrm{t}, 4 \mathrm{H}, J=6.8 \mathrm{~Hz},-\mathrm{CH}_{2}-\mathrm{N}-\mathrm{CH}_{2}-\right)$, $3.95\left(\mathrm{~d}, 2 \mathrm{H}, J=6.8 \mathrm{~Hz},-\mathrm{O}-\mathrm{CH}_{2}-\mathrm{CH}-\right)$, 6.66-6.74 (m, $3 \mathrm{H}$, Ar-H), 7.26 (d, 1H, J = 6.0 Hz, Ar-H), 7.46-7.58 (m, 2H, Ar-H), 10.69 (s, $1 \mathrm{H},-\mathrm{NH}-\mathrm{C}=\mathrm{O}$ ); ${ }^{13} \mathrm{C}$ NMR (DMSO- $d_{6}$, $100.25 \mathrm{MHz}) \delta(\mathrm{ppm}): 18.6\left(\mathrm{C}_{35}\right), 19.1\left(\mathrm{C}_{33,34}\right), 33.4\left(\mathrm{C}_{32}\right), 45.8$ $\left(\mathrm{C}_{16,20}\right), 52.9\left(\mathrm{C}_{17,19}\right), 72.5\left(\mathrm{C}_{31}\right), 105.3\left(\mathrm{C}_{1}\right), 113.8\left(\mathrm{C}_{25,27}\right)$, $115.2\left(\mathrm{C}_{5}\right), 115.4\left(\mathrm{C}_{23}\right), 116.3\left(\mathrm{C}_{11}\right), 117.2\left(\mathrm{C}_{7}\right), 124.8\left(\mathrm{C}_{3}\right), 126.4$ $\left(\mathrm{C}_{26}\right), 133.7\left(\mathrm{C}_{2,4}\right), 159.7\left(\mathrm{C}_{6}\right), 162.3\left(\mathrm{C}_{10}\right), 164.5\left(\mathrm{C}_{13}\right), 165.5$ $\left(\mathrm{C}_{24,28}\right), 166.7\left(\mathrm{C}_{8}\right), 179.6\left(\mathrm{C}_{21}\right)$; LC-MS $(\mathrm{m} / z, \%): 554\left(\mathrm{M}-\mathrm{H}^{+}\right.$, $100)$.

2.1.12. 4-[2-(3-Cyano-4-isobutoxyphenyl)-4-methylthiazole-5carbonyl]-N-(2,4-dichlorophenyl)piperazine-1-carbothioamide (8j). Light yellow solid, Yield: $82 \%, \mathrm{mp} 142-144^{\circ} \mathrm{C}$. IR $\left(\mathrm{KBr}, v \mathrm{~cm}^{-1}\right): 3267$ (-N-H, str), 3016 (=C-H, str), 2886 (-C$\mathrm{H}$, str), 2248 ( $-\mathrm{CN}$, str), 1683 (-C=O, str), 1186 (-C=S, str), 823 (-C-Cl, str). ${ }^{1} \mathrm{H}$ NMR (DMSO- $\left.d_{6}, 400 \mathrm{MHz}\right) \delta$ (ppm): $0.94\left(\mathrm{~d}, 6 \mathrm{H}, J=7.2 \mathrm{~Hz},\left(\mathrm{CH}_{3}\right)_{2}-\mathrm{CH}-\right), 1.09-1.14(\mathrm{~m}, 1 \mathrm{H}$, $\left.\left(\mathrm{CH}_{3}\right)_{2}-\mathrm{CH}-\mathrm{CH}_{2}-\right), 2.70\left(\mathrm{~s}, 3 \mathrm{H},-\mathrm{CH}_{3}\right), 3.57(\mathrm{t}, 4 \mathrm{H}, \mathrm{J}=$ $\left.7.2 \mathrm{~Hz},-\mathrm{CH}_{2}-\mathrm{N}-\mathrm{CH}_{2}-\right), 3.68\left(\mathrm{t}, 4 \mathrm{H}, \mathrm{J}=6.8 \mathrm{~Hz},-\mathrm{CH}_{2}-\mathrm{N}-\right.$ $\left.\mathrm{CH}_{2}-\right), 3.91\left(\mathrm{~d}, 2 \mathrm{H}, \mathrm{J}=6.8 \mathrm{~Hz},-\mathrm{O}-\mathrm{CH}_{2}-\mathrm{CH}-\right), 7.34-7.56(\mathrm{~m}$, $4 \mathrm{H}, \mathrm{Ar}-\mathrm{H}), 7.86$ (d, $1 \mathrm{H}, J=6.0 \mathrm{~Hz}, \mathrm{Ar}-\mathrm{H}), 8.24$ (s, 1H, Ar-H),

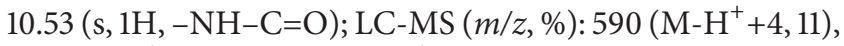
$588\left(\mathrm{M}-\mathrm{H}^{+}+2,66\right), 586\left(\mathrm{M}-\mathrm{H}^{+}, 100\right)$.

\subsection{Biological Activity}

\subsubsection{Anti-TMV Activity}

(1) Purification of the Virus. Tobacco mosaic virus (TMV) is one of the most studied plant virus and it is a major challenge for researchers to control it since it represents a major threat in the production of the cash crops like tobacco. Based on the literature reports on the thiourea and urea derivatives antiviral activity [12], the synthesized compounds $\mathbf{8}(\mathbf{a}-\mathbf{j})$ were screened for their antiviral activity against TMV.

Anti-TMV activity was evaluated by using Gooding's method [23]. The upper leaves of Nicotiana tabacum L. were inoculated with tobacco mosaic virus, selected and ground in phosphate buffer, and then filtered through a double-layer pledget. The filtrate was centrifuged at $10000 \mathrm{~g}$ bybeing treated twice with polyethylene glycol (PEG) and centrifuged again. The whole experiment was carried out at $4^{\circ} \mathrm{C}$. Absorbance of sample was measured at $260 \mathrm{~nm}$ using ultraviolet spectrophotometer. The concentration of virus was calculated by using the following formula:

$$
\text { Virus concn }=\frac{\left(\mathrm{A}_{260} \times \text { dilution ratio }\right)}{E_{1 \mathrm{~cm}}^{0.1 \%, 260 \mathrm{~nm}}} .
$$

\section{(2) In Vivo Antiviral Activity}

Protective Effect. The compound solutions were smeared on the left side, whereas the solvent served as the control on 
the right side of the growing $N$. tabacum L. leaves of the same age. The leaves were then inoculated with the virus of $6 \times 10^{-3} \mathrm{mg} / \mathrm{mL}$ after $12 \mathrm{~h}$, which were previously scattered with silicon carbide. The leaves were then washed with water and rubbed softly along the nervature twice. The local lesions appearing after inoculation of 3-4 days were counted. The inhibition rate of the tested samples was calculated according to the following formula. The experiments were repeated in triplicated and average values were taken as a final result as follows:

$$
\text { Inhibition rate } \%=\left[\frac{x-y}{x}\right] \times 100 \text {. }
$$

Here, $x=\mathrm{av}$ is the number of local lesions in control, $y=\mathrm{av}$ is the number of local lesions in tested sample. (av denotes average and control was not treated with compounds).

Inactivation Effect. The virus was inhibited by mixing with the compound solutions at the same volume for $30 \mathrm{~min}$. The mixture was then inoculated on the left side of the N. tabacum L. leaves and the right side of the leaves was inoculated with the mixture of solvent and the virus alone. The leaves were then washed with water and rubbed softly along the nervature twice. The local lesions appearing after inoculation of 3-4 days were counted. The inhibition rate of the tested samples was calculated according to the following formula. The experiments were repeated in triplicated and average values were taken as a final result as follows:

$$
\text { Inhibition rate } \%=\left[\frac{x-y}{x}\right] \times 100 \text {. }
$$

Here, $x=$ av is the number of local lesions in control, $y=$ av no. is the number of local lesions in tested sample. (av denotes average and control was not treated with compounds).

Curative Effect. The same aged growing N. tabacum L. leaves were selected. The concentration of TMV, $6 \times 10^{-3} \mathrm{mg} / \mathrm{mL}$ was dipped and inoculated on the whole leaves. Then, the leaves were washed with water and air dried for a few seconds. The compound solution was smeared on the left side and the solvent was smeared on the right side for control. After 3-4 days of inoculation, the local lesions number was then counted and recorded. The experiment was repeated three times with each tested sample. The inhibition rate of the tested samples was calculated according to the following formula (av denotes average and control was not treated with compounds):

$$
\text { Inhibition rate } \%=\left[\frac{x-y}{x}\right] \times 100 .
$$

Here, $x=$ av is the number of local lesions in control, $y=a v$ is the number of local lesions in tested sample.

(3) Change in Chlorophyll Content of TMV Inoculated Tobacco Leaves after Treatment [24]. The same age growing and healthy tobacco plant leaves were selected for viral tests. Foremost, the 7th leaf was selected and the whole leaf was inoculated with the virus followed by a simple water to rinse for surface sterilization. Leaves were dried and coated with virus inoculums for further analysis. Measurements were made on every second day for chlorophyll content. To determine chlorophyll content, the leaf samples were separated from plant and weighted accurately followed by putting it into $5 \mathrm{~mL}$ of $80 \%$ acetone at a temperature of $4^{\circ} \mathrm{C}$. The dark extraction was performed overnight. The chlorophyll contents of tobacco leaves extracted over night are placed in a $1 \mathrm{~cm}$ thick cuvette with $80 \%$ of acetone as blank. The UVVisible spectrometer was employed to measure absorbance of chlorophyll content at $645 \mathrm{~nm}$ and $663 \mathrm{~nm}$ to evaluate the Chl-a + Chl-b concentrations using the following formula.

Chl-a $=12.7 \mathrm{~A}_{663}-2.69 \mathrm{~A}_{645} ; \mathrm{Chl}-\mathrm{b}=22.7 \mathrm{~A}_{645}-4.68 \mathrm{~A}_{663}$.

Total chlorophyll content Chl-a + Chl-b $=\left[20.2 \mathrm{~A}_{645} \pm\right.$ $\left.8.02 \mathrm{~A}_{663}\right] V \times W / 1000$.

In the above formula, $\mathrm{A}_{645}$ and $\mathrm{A}_{663}$ are the absorbance values at the corresponding wave lengths, " $V$ " is the volume of extraction and " $W$ " is the weight of fresh leaf. Finally, chlorophyll content is expressed in $\mathrm{mg} \cdot \mathrm{g}^{-1} \mathrm{FW}$.

\subsubsection{Antimicrobial Activity}

(1) Antibacterial Activity. Disc diffusion method [25, 26] was employed to screen the significant antibacterial activity of the synthesized urea and thiourea derivatives $\mathbf{8}(\mathbf{a}-\mathbf{j})$ against different bacteria such as Streptococcus aureus (ATCC-25923), Pseudomonas aeruginosa (ATCC-25619), and Escherichia coli (ATCC-9637). Ciprofloxacin was used as a standard drug for antibacterial studies. A standard inoculums of $1-2 \times$ $10^{-7}$ c.f.u/mL (0.5 McFarland standards) was introduced on to the surface of sterile agar plates, and a sterile glass spreader was used for even distribution of the inoculums. Discs measuring $6 \mathrm{~mm}$ in diameter were prepared from Whatman No. 1 filter paper and sterilized by dry heat at $140^{\circ} \mathrm{C}$ for an hour. The dry sterilized discs soaked in a known concentration $(200 \mu \mathrm{g} / \mathrm{mL})$ of the test compounds were placed in nutrient agar medium. Blank test showed that DMSO used in the preparation of the test solutions does not affect the bacteria. The plates after inoculation were inverted and incubated for $24 \mathrm{~h}$ at $37^{\circ} \mathrm{C}$. The zone of inhibition around the disc which was calculated edge to edge zone of the confluent growth usually corresponds to the sharpest edge of the zone and was measured in millimeters. All tests were repeated three times and average data was taken as final result. Minimum inhibitory concentrations (MICs) were also determined by microbroth dilution technique [27-29]. Specifically $0.1 \mathrm{~mL}$ of standardized inoculum $\left(1-2 \times 10^{7}\right.$ c.f.u/mL $)$ was added to test tubes and incubated for $24 \mathrm{~h}$ at $37^{\circ} \mathrm{C}$ and two controls were maintained for each test sample. The growth was monitored visually and spectrophotometrically. The lowest concentration (highest dilution) required to arrest the growth of bacteria was regarded as minimum inhibitory concentration (MIC).

(2) Antifungal Activity. The antifungal activity of the titled urea and thiourea derivatives $\mathbf{8}(\mathbf{a}-\mathbf{j})$ were screened against fungal strains such as Aspergillus flavus (MTCC-1884), Aspergillus niger (MTCC-1881), and Candida albicans (ATCC- 2091) using agar disc-diffusion method [27-29]. The fungal strains were maintained on Potato Dextrose Agar 
TABle 1: Physical data of titled urea and thiourea derivatives $\mathbf{8}(\mathbf{a}-\mathbf{j})$.

\begin{tabular}{|c|c|c|c|c|}
\hline Compound & Product & Reaction time (h) & Yield (\%) & m.p $\left({ }^{\circ} \mathrm{C}\right)$ \\
\hline 4 & & 8 & 94 & $154-156$ \\
\hline $8 \mathbf{a}$ & & 3 & 85 & $182-184$ \\
\hline $8 b$ & & 4 & 81 & $163-165$ \\
\hline $8 \mathrm{c}$ & & 2.5 & 89 & $176-178$ \\
\hline $8 d$ & & 2.5 & 90 & $181-183$ \\
\hline $8 e$ & & 3 & 86 & $201-203$ \\
\hline $8 f$ & & 3 & 83 & $167-169$ \\
\hline $8 g$ & & 2.5 & 86 & $171-173$ \\
\hline $8 \mathrm{~h}$ & & 3 & 83 & $188-190$ \\
\hline $8 \mathrm{i}$ & & 3.5 & 83 & $214-216$ \\
\hline $8 \mathbf{j}$ & & 4 & 82 & $142-144$ \\
\hline
\end{tabular}




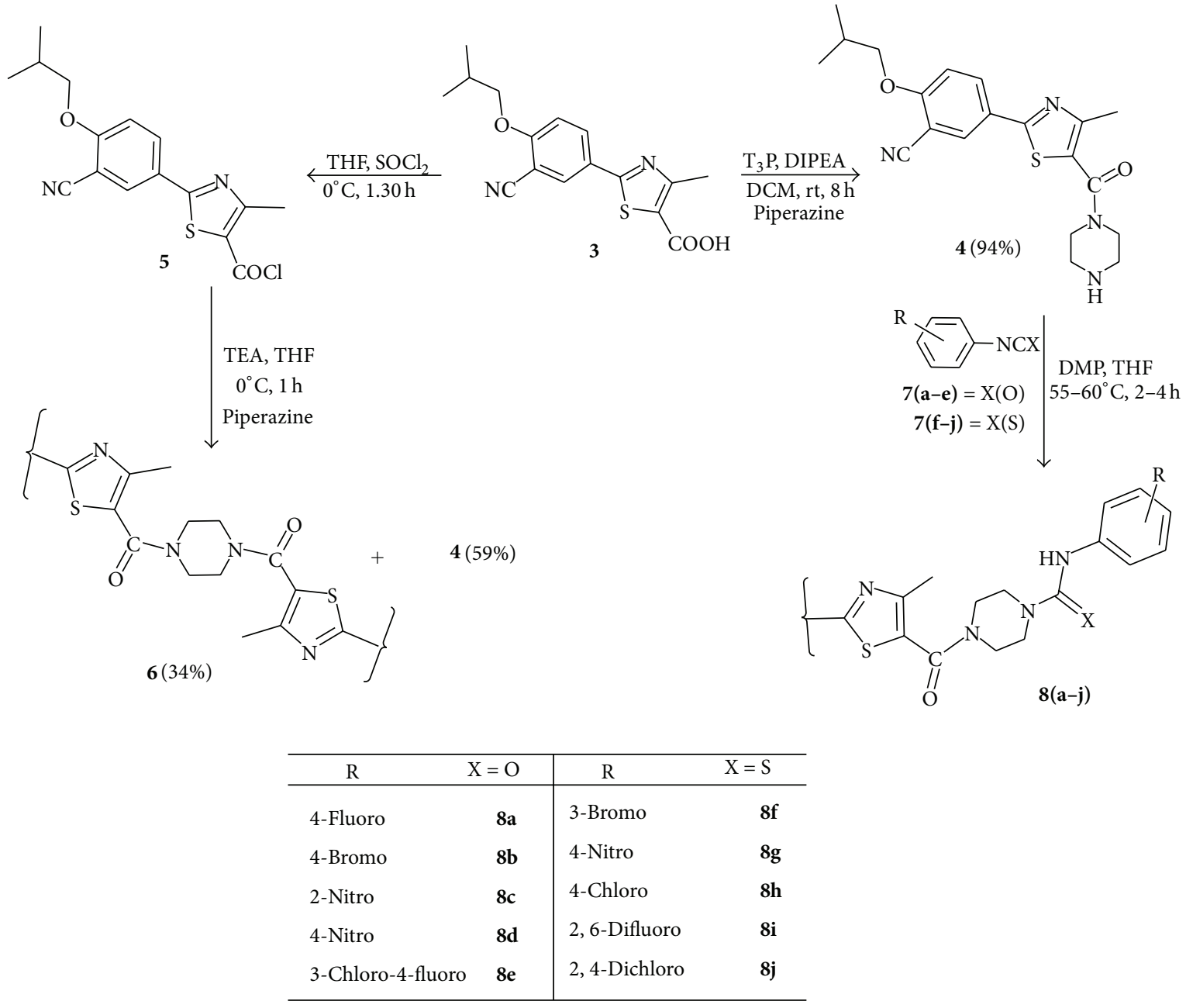

Scheme 1: Synthesis of urea and thiourea derivatives of piperazine tagged with febuxostat.

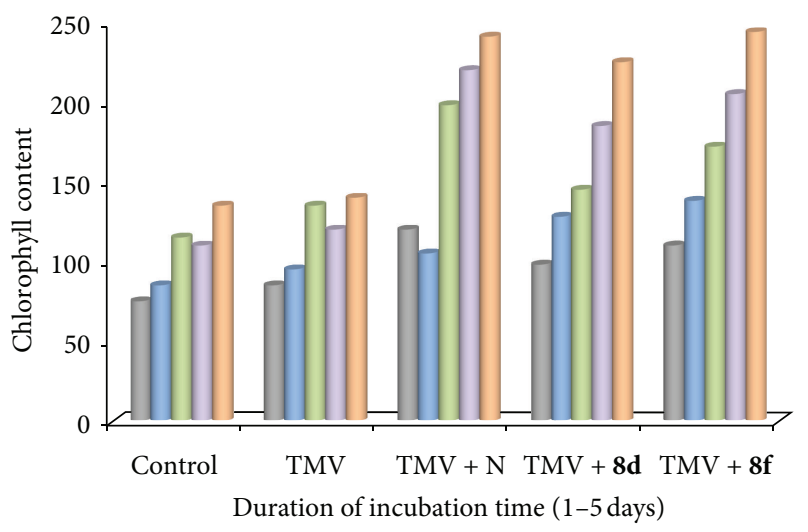

FIGURE 2: Change in the chlorophyll content in the tobacco leaves after treatment with $\mathbf{8 d}$ and $\mathbf{8 f}$.

(PDA) medium (Hi-Media). A loop full of culture from the slant was inoculated into the Potato Dextrose broth and incubated at $37^{\circ} \mathrm{C}$ for $48-72 \mathrm{~h}$. This culture $(0.1 \mathrm{~mL})$ was spread on the potato dextrose agar plate and a sterile glass spreader was used for even distribution of the inoculums.
All the compounds were dissolved in dimethyl sulfoxide (DMSO). Sterile discs of Whatman No. 1 filter paper of about $6 \mathrm{~mm}$ diameter were dried and soaked in $200 \mu \mathrm{g} / \mathrm{mL}$ concentration of the test samples. The soaked discs were impregnated on the surface of the media and incubated for $48-72 \mathrm{~h}$ at $37^{\circ} \mathrm{C}$. Blank test showed that DMSO used in the preparations of the test solutions does not affect the test fungi. The zone of inhibition around the disc was the calculated edge to edge zone of the confluent growth which usually corresponds to the sharpest edge of the zone and was measured in millimeters. All tests were repeated three times and average data was taken as final result. Fluconazole was used as a standard drug for antifungal study. Minimum Inhibitory Concentration (MIC) of the tested samples was determined by micro-broth-dilution method [27-29]. Specifically $0.1 \mathrm{~mL}$ of standardized inoculum $(1-2 \times$ $10^{7}$ c.f.u/mL) was added to each test tube. The tubes were incubated aerobically at $37^{\circ} \mathrm{C}$ for $48-72 \mathrm{~h}$. Control was maintained for each test sample. The lowest concentrations (highest dilution) of test compound that produced no visible signs of fungal growth (no turbidity) when compared with the control tubes were regarded as MICs. 
TABLE 2: The inhibitory activity of the titled urea and thiourea derivatives $\mathbf{8}(\mathbf{a}-\mathbf{j})$ on TMV.

\begin{tabular}{lccc}
\hline Compound $^{\text {Inactivation rate }}$ & $\begin{array}{c}\text { Protective effect } \\
(\%) \pm S D\end{array}$ & $\begin{array}{c}\text { Curative effect } \\
(\%) \pm S D\end{array}$ \\
\hline $\mathbf{4}$ & $57.54 \pm 0.18$ & $39.82 \pm 0.97$ & $36.02 \pm 0.72$ \\
$\mathbf{8 a}$ & $74.41 \pm 0.56$ & $41.24 \pm 0.76$ & $52.73 \pm 1.43$ \\
$\mathbf{8 b}$ & $72.55 \pm 0.74$ & $40.57 \pm 1.28$ & $49.75 \pm 0.76$ \\
$\mathbf{8 c}$ & $78.43 \pm 1.01$ & $52.31 \pm 0.84$ & $51.28 \pm 0.69$ \\
$\mathbf{8 d}$ & $85.72 \pm 0.33$ & $58.72 \pm 1.18$ & $57.34 \pm 0.82$ \\
$\mathbf{8 e}$ & $65.28 \pm 0.97$ & $39.86 \pm 0.49$ & $49.28 \pm 0.86$ \\
$\mathbf{8 f}$ & $85.93 \pm 0.54$ & $58.29 \pm 0.76$ & $56.31 \pm 0.97$ \\
$\mathbf{8 g}$ & $64.56 \pm 1.27$ & $45.53 \pm 0.86$ & $48.29 \pm 1.08$ \\
$\mathbf{8 h}$ & $81.33 \pm 0.79$ & $58.88 \pm 0.78$ & $56.03 \pm 1.10$ \\
$\mathbf{8 i}$ & $72.74 \pm 0.48$ & $50.73 \pm 1.25$ & $42.49 \pm 0.92$ \\
$\mathbf{8 j}$ & $63.26 \pm 0.98$ & $47.96 \pm 0.44$ & $46.23 \pm 0.75$ \\
Stand & $88.45 \pm 0.68$ & $59.62 \pm 0.74$ & $57.27 \pm 0.54$ \\
\hline
\end{tabular}

${ }^{\mathrm{a}}$ The title compounds tested at $500 \mu \mathrm{g} / \mathrm{L}$.

Stand: Ningnanmycin, SD: standard deviation.

\section{Results and Discussion}

3.1. Chemistry. The synthesis of urea $\mathbf{8}(\mathbf{a}-\mathbf{e})$ and thiourea $\mathbf{8}(\mathbf{f}-\mathbf{j})$ derivatives of piperazine tagged with febuxostat was accomplished. An intermediate, 2-isobutoxy-5-(4-methyl-2(piperazine-1-carbonyl)thiazol-5-yl)benzonitrile (4) (Scheme 1) was synthesized according to two methods.

Primarily, we were attempting to synthesize key intermediate 4 by reacting piperazine with 5-(3-isobutoxyphenyl)4-methylthiazole-2-carbonyl chloride (5), which was obtained by the conversion of carboxylic acid group in febuxostat (3) into acid chloride in the presence of thionyl chloride at $0^{\circ} \mathrm{C}$. This reaction afforded $59 \%$ of the desired key intermediate 4 along with $34 \%$ of dimerized product, $5,5^{\prime}$ (2,2' -(piperazine-1,4-diylbis(oxomethylene))bis(4-methylthiazole-5,2-diyl))bis(2-isobutoxybenzonitrile) (6). Also, the same model reaction was attempted at $-15^{\circ} \mathrm{C}$ to improve the yield of the desired product 4 . Little enhancement in the yield of compound 4 (68\%) was observed. Later, another method was adopted to prevent the formation of dimerized product; the carboxylic acid group in febuxostat was condensed with piperazine in $\mathrm{DCM}$ in the presence of $\mathrm{T}_{3} \mathrm{P}$ (propylphosphonic anhydride) at room temperature with vigorous stirring. The reaction provided a high yield of $94 \%$ desired key intermediate 4 with simple work-up procedure such as filtration and recrystallization from methanol. Finally, title urea and thiourea derivatives $\mathbf{8}(\mathbf{a}-\mathbf{j})$ were achieved in high yields through the reaction of intermediate 4 with various pharmacologically active functionalized phenyl isocyanates $7(\mathbf{a}-\mathbf{e})$ and phenyl isothiocyanates $7(\mathbf{f}-\mathbf{j})$ in tetrahydrofuran (THF) using N, N-dimethylpiperazine as a base. It was also observed that isocyanates and isothiocyanates containing electron-withdrawing functionalities $(\mathbf{8 c}, \mathbf{8 d}, \mathbf{8 g}$, and 8i) gave good yields in comparison with substrates bearing donating functional groups ( $\mathbf{8 b}$ and $\mathbf{8 f})$. The synthesized compounds were reported for the first time as per the literature knowledge. The physical characteristics of the title compounds are represented in Table 1.

The structures of the newly synthesized compounds $\mathbf{8}(\mathbf{a}-\mathbf{j})$ were characterized by IR, ${ }^{1} \mathrm{H} /{ }^{13} \mathrm{C}$ NMR, mass spectral data, and elemental analysis. IR spectrum of compound 4 displayed strong absorption band at $3324 \mathrm{~cm}^{-1}$ for -NH (str) of piperazine, and the disappearance of the absorption band for $-\mathrm{OH}$ stretching of $-\mathrm{COOH}$ in febuxostat at $3418 \mathrm{~cm}^{-1}$ indicated the formation of intermediate compound, 2-isobutoxy-5-(4-methyl-2-(piperazine1-carbonyl)thiazol-5-yl)benzonitrile (4). The appearance of the bands in all IR spectra of synthesized compounds in the region of $1720-1640$ for $(-\mathrm{C}=\mathrm{O})$, and $1660-1590$ $(-\mathrm{C}=\mathrm{S})$ indicated the formation of titled urea and thiourea derivatives $\mathbf{8}(\mathbf{a}-\mathbf{j})$, respectively. In ${ }^{1} \mathrm{H}-\mathrm{NMR}$ spectrum of the compound $\mathbf{4}$, the chemical shift at $\delta 2.85$ is assigned to $-\mathrm{NH}$ proton of intermediate 4 , and the disappearance of chemical shift value at $\delta 11.3$ of $-\mathrm{COOH}$ in febuxostat indicated the formation of intermediate 4 . Chemical shift values in the regions $8.15-10.98 \mathrm{ppm}$ and $6.82-8.78 \mathrm{ppm}$ are assigned to protons of $-\mathrm{NH}$ in urea/thiourea derivatives and aromatic protons, respectively. ${ }^{13} \mathrm{C}-\mathrm{NMR}$ spectra gave signals in the regions $154.4-168.3 \mathrm{ppm}$ and $158.4-179.9 \mathrm{ppm}$ for $-\mathrm{C}=\mathrm{O}$ and $-\mathrm{C}=\mathrm{S}$, respectively. The appearance of the molecular ion peaks in the mass spectra and the correlated composition of tested compounds in elemental analysis with calculated composition have given further evidence for the characterization of the synthesized compounds. The spectral data of titled compounds are presented in the experimental part.

3.2. Biological Activity. Antiviral activity of title compounds $\mathbf{8}(\mathbf{a}-\mathbf{j})$ was screened against Tobacco mosaic virus and the results are given in Tables 2 and 3 and Figure 2. The results of in vivo inactivation rate, protective effect, and curative effects of the urea and thiourea derivatives $8(\mathbf{a}-\mathbf{j})$ against TMV are presented in Table 2 . All the title compounds exhibited potent to moderate inhibition activity against TMV. The 4-nitrophenyl urea substituted compound 8d and 3bromophenyl thiourea substituted compound $\mathbf{8 f}$ showed high inactivation of infection, that is, inhibition rate of $\mathbf{8 d}$ and $\mathbf{8 f}$ are $85.72 \pm 0.33$ and $85.93 \pm 0.54$, respectively. In in vivo, for $\mathbf{8 d}$ and $\mathbf{8 f}$, infection protective effects are $58.72 \pm$ 1.18 and $58.29 \pm 0.76$ and infection curative effects are $57.34 \pm 0.82$ and $56.31 \pm 0.97$, respectively. The Extent of viral infection in plants leads to proliferation expansion and destruction of the chloroplast, and these factors retarding the production of chlorophyll, subsequently causing leaf chlorosis and mosaic. It reduces the photosynthetic pigment in TMV infected leaves. The host's resistance of TMV infected leaves is enhanced when these leaves were treated with antiviral agents. Furthermore, the efficacy of the potent titled compounds $\mathbf{8 d}, \mathbf{8 f}$ on the chlorophyll content in tobacco was examined and results are tabulated in Table 3 and Figure 2. The biological data revealed that the chlorophyll content in virus inoculated tobacco leaves was increased during 1-5 days and reached the highest value on the 5th day when these leaves are sprayed with potent synthesized compounds 


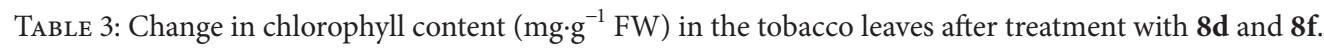

\begin{tabular}{|c|c|c|c|c|c|}
\hline Duration of incubation $^{\mathrm{b}}$ (days) & Control & TMV & $\mathrm{TMV}+\mathrm{N}$ & $\mathrm{TMV}+\mathbf{8 d}$ & $\mathrm{TMV}+\mathbf{8 f}$ \\
\hline 1 & 75 & 85 & 120 & 98 & 110 \\
\hline 2 & 85 & 95 & 105 & 128 & 138 \\
\hline 3 & 115 & 135 & 198 & 145 & 172 \\
\hline 4 & 110 & 120 & 220 & 185 & 205 \\
\hline 5 & 135 & 140 & 241 & 225 & 244 \\
\hline
\end{tabular}

${ }^{\mathrm{b}}$ Incubation period in days, TMV: Tobacco mosaic virus, N: Ningnanmycin.

TABLE 4: Antimicrobial activity of the titled urea and thiourea derivatives $\mathbf{8}(\mathbf{a}-\mathbf{j})$.

\begin{tabular}{|c|c|c|c|c|c|c|c|c|c|c|c|c|}
\hline \multirow{3}{*}{ Compd. } & \multicolumn{6}{|c|}{ Bacterial culture } & \multicolumn{6}{|c|}{ Fungal culture } \\
\hline & \multicolumn{2}{|c|}{ S. aureus } & \multicolumn{2}{|c|}{ P. aeruginosa } & \multicolumn{2}{|c|}{ E. coli } & \multicolumn{2}{|c|}{ A. flavus } & \multicolumn{2}{|c|}{ A. niger } & \multicolumn{2}{|c|}{ C. albicans } \\
\hline & $\mathrm{ZOI}^{\mathrm{c}}$ & MIC & $\mathrm{ZOI}^{\mathrm{a}}$ & MIC & $\mathrm{ZOI}^{\mathrm{a}}$ & MIC & $\mathrm{ZOI}^{\mathrm{a}}$ & MIC & $\mathrm{ZOI}^{\mathrm{a}}$ & MIC & $\mathrm{ZOI}^{\mathrm{a}}$ & MIC \\
\hline 4 & 14.9 & 60 & 13.4 & 65 & 12.7 & 50 & 10.9 & 65 & 10.5 & 65 & 11.3 & 45 \\
\hline $8 \mathbf{a}$ & 20.8 & 17 & 19.9 & 20 & 23.8 & 17 & 18.6 & 30 & 19.3 & 30 & 18.8 & 35 \\
\hline $8 b$ & 16.3 & 40 & 19.2 & 30 & 17.3 & 45 & 13.8 & 80 & 13.7 & 80 & 16.3 & 40 \\
\hline $8 c$ & 17.1 & 18 & 18.5 & 45 & 17.6 & 55 & 14.3 & 80 & 14.4 & 75 & 14.5 & 55 \\
\hline $8 d$ & 19.8 & 20 & 20.5 & 20 & 24.7 & 15 & 19.9 & 20 & 19.6 & 30 & 19.8 & 20 \\
\hline $8 \mathrm{e}$ & 18.9 & 30 & 20.8 & 20 & 19.4 & 35 & 17.5 & 45 & 16.8 & 65 & 17.7 & 30 \\
\hline $8 f$ & 20.1 & 15 & 19.8 & 25 & 20.5 & 30 & 19.2 & 20 & 20.1 & 20 & 19.3 & 25 \\
\hline $8 \mathrm{~g}$ & 17.8 & 45 & 17.3 & 35 & 18.3 & 70 & 16.4 & 50 & 17.8 & 40 & 16.4 & 30 \\
\hline $8 \mathrm{~h}$ & 16.1 & 40 & 16.2 & 35 & 15.2 & 70 & 13.9 & 80 & 14.5 & 70 & 13.8 & 80 \\
\hline $8 \mathrm{i}$ & 16.7 & 30 & 18.8 & 40 & 17.9 & 45 & 16.1 & 45 & 18.3 & 35 & 15.9 & 70 \\
\hline $8 \mathbf{j}$ & 19.7 & 25 & 20.8 & 20 & 22.8 & 20 & 19.0 & 25 & 19.6 & 25 & 19.7 & 20 \\
\hline Ciprofloxacin & 22 & 04 & 23 & 05 & 27 & 04 & - & - & - & - & - & - \\
\hline Fluconazole & - & - & - & - & - & - & 21 & 04 & 23 & 04 & 22 & 05 \\
\hline
\end{tabular}

ZOI: zone of inhibition in $\mathrm{mm}$.

${ }^{\mathrm{c}}$ Concentration of compounds at $200 \mu \mathrm{g} / \mathrm{mL}$.

8d and 8f. Among them, compound $8 \mathbf{f}$ exhibited better effectiveness and 8d showed less potency when compared with the standard, Nignanmycin. The compounds 8d and $\mathbf{8 f}$ significantly enhanced the chlorophyll content, indicating the demolish of virus of the tobacco and enhancing hosts resistance towards diseases.

The title compounds were screened against $S$. aureus, $P$. aeruginosa, and $E$. coli bacterial strains and against $A$. flavus, A. niger, and C. albicans fungal strains using discdiffusion method. The minimum inhibitory concentration of the tested samples was also examined and the results are presented in Table 4. Groups like 4-fluorophenyl in 8a, 4nitrophenyl in $\mathbf{8 d}$ of urea derivatives, and 3-bromophenyl in $\mathbf{8 f}, 2,4$-dichlorophenyl in $\mathbf{8 j}$ of thiourea derivatives might be responsible for potent antimicrobial activity. Compound $\mathbf{8 e}$ exhibited potent activity against $P$. aeruginosa. Compound $\mathbf{8 f}$ has the lowest MIC value (15) against S. aureus.

All the compounds exhibited potent to moderate inhibitory activities against viral, bacterial, and fungal organisms. Especially the compounds $\mathbf{8 a}, \mathbf{8 d}, \mathbf{8 f}$, and $\mathbf{8 j}$ exhibited good results against the above organisms at lower concentration when compared with other compounds.

\section{Conclusion}

In conclusion, a series of new urea and thiourea derivatives of piperazine tagged with febuxostat drug was accomplished in high yields. In the development of the target molecules, the piperazine is effectively coupled with febuxostat in high yields in the presence of $\mathrm{T}_{3} \mathrm{P}$ reagent. The antiviral activity against TMV and antimicrobial activity of the titled compounds were evaluated. The compounds 8d (4-nitrophenyl urea substituted derivative) and $\mathbf{8 f}$ (3-bromophenyl thiourea substituted derivative) were found to be promising antiviral agents and compounds 8a (4-fluorophenyl urea substituted derivative) and $\mathbf{8 j}$ (2, 4-dichlorophenyl thiourea substituted derivative) exhibited good antimicrobial activity. With little exception, overall, it was observed that the titled compounds meritoriously worked as antiviral agents.

\section{Conflict of Interests}

The authors have declared that there is no conflict of interests.

\section{Acknowledgments}

The authors Reddivari Chenna Krishna Reddy, Syed Rasheed, and Devineni Subba Rao are expressing their acknowledgement to UGC-BSR, New Delhi, for awarding Junior Research Fellowship under RFSMS scheme. The authors are also thankful to Hyderabad Central University (Hyderabad) and Department of Biochemistry (S. V. University, Tirupati) for providing instrumentation facilities and biological activity, respectively. 


\section{References}

[1] T. Ardan, J. Kovačeva, and J. Čejková, “Comparative histochemical and immunohistochemical study on xanthine oxidoreductase/xanthine oxidase in mammalian corneal epithelium," Acta Histochemica, vol. 106, no. 1, pp. 69-75, 2004.

[2] R. C. Lawrence, C. G. Helmick, and F. C. Arnett, "Estimates of the prevalence of arthritis and selected musculo skeletal disorders in the United States," Arthritis \& Rheumatism, vol. 41, pp. 778-799, 1998.

[3] K.-H. Yu and S.-F. Luo, "Younger age of onset of gout in Taiwan," Rheumatology, vol. 42, no. 1, pp. 166-170, 2003.

[4] H.-Y. Chang, W.-H. Pan, W.-T. Yeh, and K.-S. Tsai, "Hyperuricemia and gout in Taiwan: results from the nutritional and health survey in Taiwan (1993-96)," Journal of Rheumatology, vol. 28, no. 7, pp. 1640-1646, 2001.

[5] T. Spector, "Oxypurinol as an inhibitor of xanthine oxidasecatalyzed production of superoxide radical," Biochemical Pharmacology, vol. 37, no. 2, pp. 349-352, 1988.

[6] R. Khosravan, B. S. K. Erdman, L. Vernillet et al., "Effect of febuxostat on pharmacokinetics of desipramine, a CYP2D6 substrate, in healthy subjects effect of febuxostat on pharmacokinetics of desipramine, a CYP2D6 substrate, in healthy subjects," Clinical Pharmacology \& Therapeutics, vol. 77, p. 43, 2005.

[7] S. P. Bruce, "Febuxostat: a selective xanthine oxidase inhibitor for the treatment of hyperuricemia and gout," Annals of Pharmacotherapy, vol. 40, no. 12, pp. 2187-2194, 2006.

[8] C. L. Gray and N. E. Walters-Smith, "Febuxostat for treatment of chronic gout," American Journal of Health-System Pharmacy, vol. 68, no. 5, pp. 389-398, 2011.

[9] B. Szukalski, "Derivatives of piperazine, pyrrolidine, benzimidazole and tryptamine-new drugs modified," Problemy Kryminalistyki, vol. 249, pp. 9-15, 2005.

[10] H. Pluempe and W. Pulls, Chemical Abstracts, vol. 74, 1251154n, 1971.

[11] S. S. Bahekar and D. B. Shinde, "Synthesis and anti-inflammatory activity of some [4,6-(4-substituted aryl)-2-thioxo-1,2,3, 4-tetrahydro-pyrimidin-5-yl]-acetic acid derivatives," Bioorganic and Medicinal Chemistry Letters, vol. 14, no. 7, pp. 17331736, 2004.

[12] D. K. Yuan, D. Q. Zhang, R. X. Li, D. Q. Wang, and X. L. Yang, "Synthesis and anti-TMV activity of novel $N$-(pyrimidin-5-yl)$N^{\prime}$-phenylureas," Chinese Chemical Letters, vol. 22, no. 1, pp. 1820, 2011.

[13] S. N. Sawhney, J. Singh, and O. P. Bansal, "Synthesis and antiinflammatory activity of some 6 [2 amino (and substituted amino) 4 thiazolyl] benzothiazoles," Journal of the Indian Chemical Society, vol. 52, no. 6, pp. 561-562, 1975.

[14] P. A. Yonova and G. M. Stoilkova, "Synthesis and biological activity of urea and thiourea derivatives from 2-aminoheterocyclic compounds," Journal of Plant Growth Regulation, vol. 23, no. 4, pp. 280-291, 2004.

[15] G. E. Hardtman, G. Linder, G. P. Mattener, G. W. Salmound, and M. Denger, Chemical Abstracts, vol. 80, 83046v, 1974.

[16] W. T. Hoeve and H. Wynberg, "Chiral cyclic amidines," Synthetic Communications, vol. 24, pp. 2215-2221, 1994.

[17] L. Lardicci, C. Battistini, and R. Menicagli, "Synthesis of some optically active thiazole derivatives," Journal of the Chemical Society, Perkin Transactions 1, vol. 13, pp. 344-346, 1974.

[18] A. A. Tsurkan, A. I. Frolova, N. I. Pospelov, and L. A. Dorofeeva, "Mobility of hydrogen atoms of the methylene group of some acyl pseudo thio hydantoins," Khimiko Farmatsevticheskii Zhurnal, vol. 9, no. 6, pp. 12-15, 1975.

[19] L. R. Rosatti, Chemical Abstracts, vol. 80, 82954c, 1974.

[20] H. Nakano, H. Haroda, T. Funaoka, and K. Akashi, Chemical Abstracts, vol. 78, 43086, 1973.

[21] E. A. Sausville, "Protein kinase antagonists: interim challenges and issues," Anticancer Drug Design, vol. 15, no. 1, pp. 1-2, 2000.

[22] R. S. Rogers and M. K. Stern, "An improved synthesis of the phosphonic acid analog of tryptophan," Synlett, vol. 9, article 708, 1992.

[23] G. V. Gooding Jr. and T. T. Hebert, "A simple technique for purification of tobacco mosaic virus in large quantities," Phytopathology, vol. 57, no. 11, p. 1285, 1967.

[24] Y. S. Peng and E. Liu, "Studies of method on extract chlorophyll a and b," Acta Agricultural Universitas Pekinensis, vol. 18, pp. 247-250, 1992.

[25] R. Cruickshank, J. P. Duguid, B. P. Marmion, and R. H. A. Swain, Medicinal Microbiology, Churchill Livingstone, New York, NY, USA, 12th edition, 1975.

[26] A. H. Collins, Microbiological Methods, Butterworth, London, UK, 2nd edition, 1976.

[27] G. H. Bonjar Shahidi, "Evaluation of antibacterial properties of Iranian medicinal plants against Micrococcus luteus, Serratia marcescens, Klebsiella pneumonia and Bordetella bronchoseptica," Asian Journal of Plant Sciences, vol. 3, pp. 82-86, 2004.

[28] National Committee for Clinical Laboratory Standards, Methods for Dilution, Antimicrobial Susceptibility Tests for Bacteria That Grow Aerobically, 5th edition, 2000.

[29] A. W. Bauer, M. M. Kirby, J. C. Sherris, and M. Truck, "Antibiotic susceptibility testing by a standardized single disc method," American Journal of Clinical Pathology, vol. 45, pp. 493-496, 1966. 

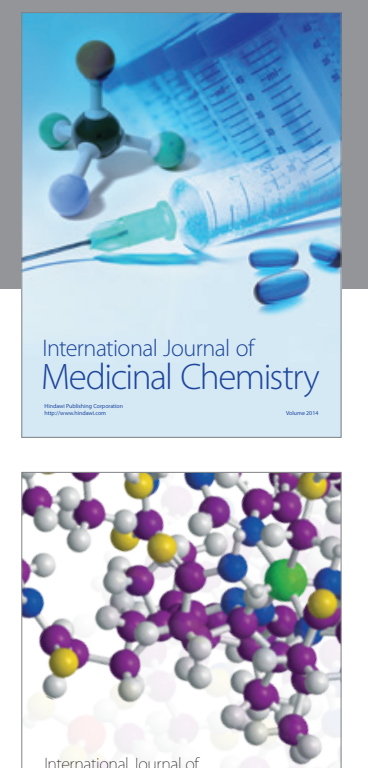

\section{Carbohydrate} Chemistry

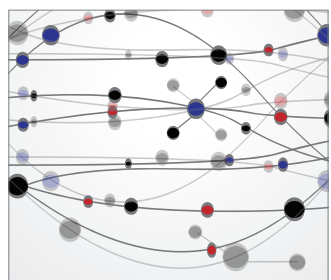

The Scientific World Journal
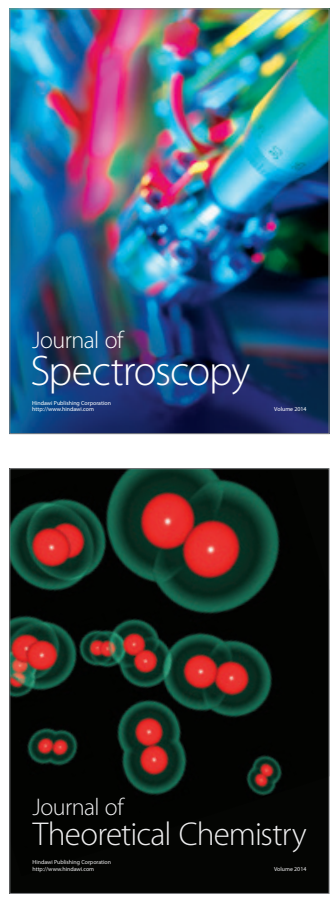
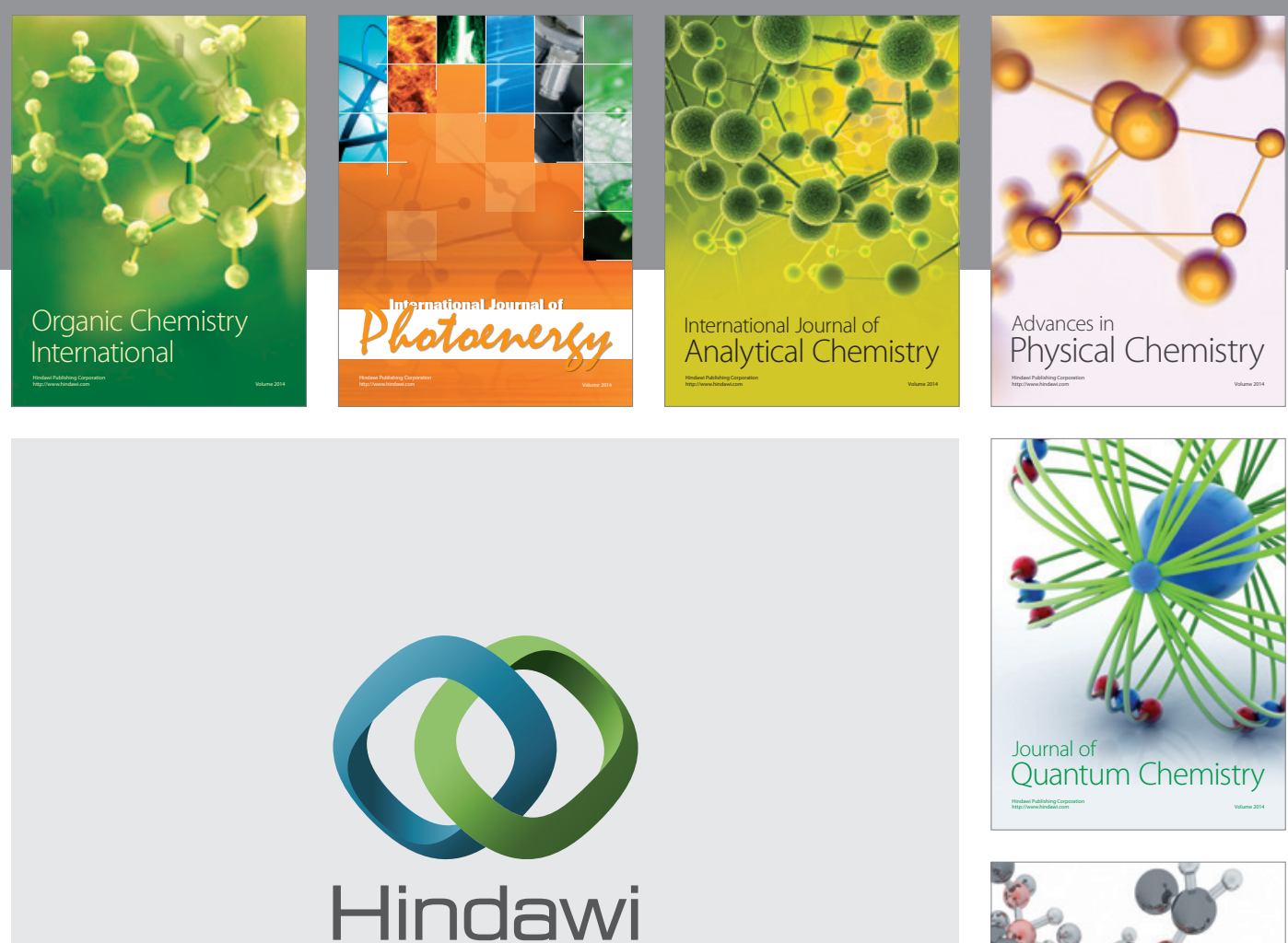

Submit your manuscripts at

http://www.hindawi.com

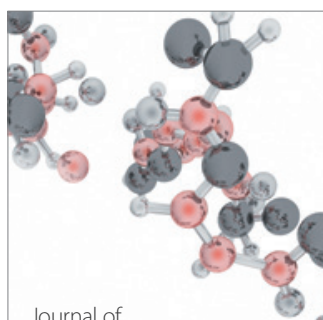

Analytical Methods

in Chemistry

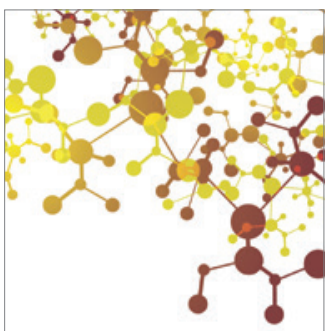

Journal of

Applied Chemistry

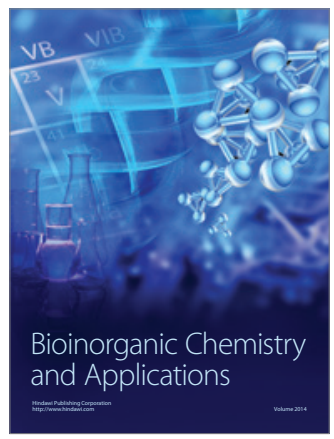

Inorganic Chemistry
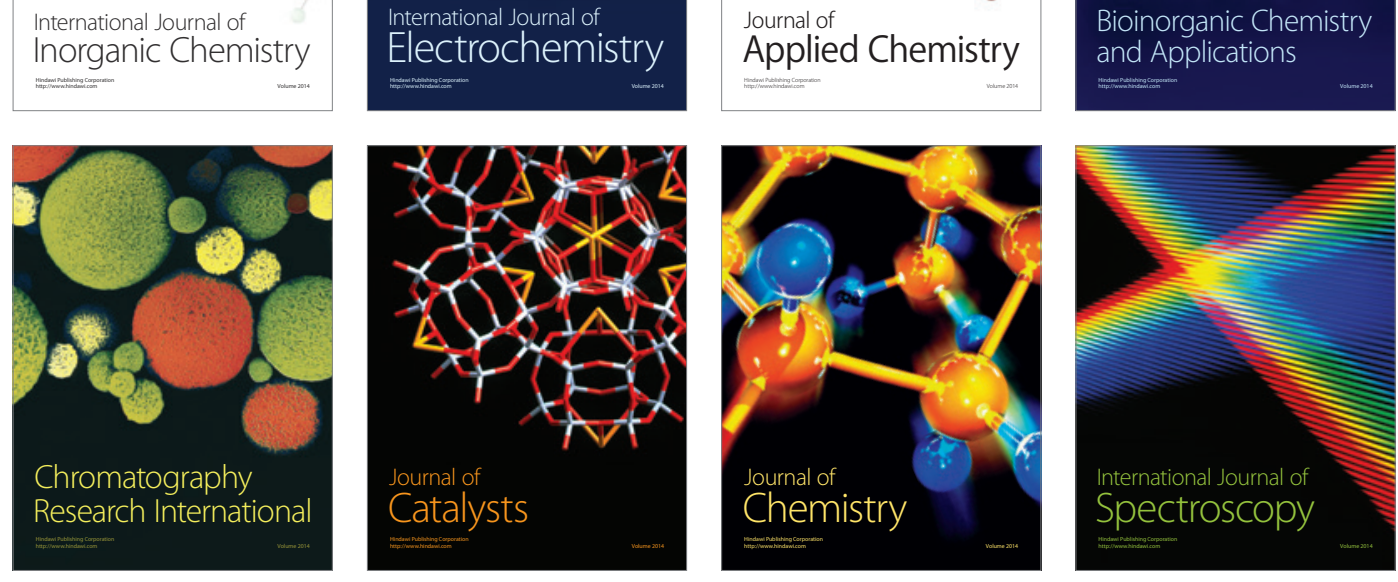